\title{
Comparison between SAC405 Lead-free Solders and EN(P)EPIG and EN(B)EPIG Surface Finishes
}

\author{
O. Saliza Azlina ${ }^{1, a}$, A. Ourdjini, ${ }^{2, b}$, and M.H.I Ibrahim ${ }^{1, c}$ \\ ${ }^{1}$ Faculty of Mechanical and Manufacturing Engineering, Universiti Tun Hussein Onn Malaysia, \\ Johor, Malaysia \\ ${ }^{2}$ Faculty of Mechanical Engineering, Universiti Teknologi Malaysia, Johor, Malaysia \\ asalizaz@uthm.edu.my, bourdjini@fkm.utm.my, ${ }^{\mathrm{c}}$ mdhalim@uthm.edu.my
}

Keywords: Soldering; Lead-free solder; Intermetallic compounds; Isothermal Aging; Surface finish

\begin{abstract}
In electronics industries, most of them had to shifted their solder materials from leaded solders into lead-free solders due to the environmental concerns and follow the legislation of Restriction of use Hazardous Substances (RoHS). Thus, Sn-Ag-Cu solder is one of the choices that can replace the leaded solder and also offer better properties. This study investigates the comparison between Sn-4.0Ag-0.5Cu (SAC405) and EN(P)EPIG and EN(B)EPIG surface finishes. Reliability of solder joint has been assessed by performing solid state isothermal aging at $150^{\circ} \mathrm{C}$ for 250 up to 2000 hours. After reflow soldering process, $(\mathrm{Cu}, \mathrm{Ni})_{6} \mathrm{Sn}_{5}$ intermetallic compound (IMC) is dominated at near centre of solder meanwhile $(\mathrm{Ni}, \mathrm{Cu})_{3} \mathrm{Sn}_{4}$ IMC is dominated at near outside of solder ball. Moreover, aging time resulted in an increase in thickness and changed the morphology into more spherical, dense and large grain size. Analysis by optical microscope revealed that the IMC thickness of EN(B)EPIG produced thicker IMC compared to EN(P)EPIG surface finish during reflow as well as isothermal aging.
\end{abstract}

\section{Introduction}

Owing to legislations, especially in Europe (WEEE and RoHS), and the market demand, the elimination of lead in electronic manufacturing is becoming focused these years. After July 1, 2006, the RoHS is taking effect and electronics products sold to Europe must not contain lead [1]. Thus, the $\mathrm{Sn}-\mathrm{Ag}-\mathrm{Cu}$ solder is one of the choices that can replace the leaded solder and commonly used in surface mount technology (SMT) assembly for microelectronics into industrial production [2].

An effective approach for retarding the excessive growth of IMCs is to insert Ni-based metallization layer between the solder and the $\mathrm{Cu}$ conducting pad. In this approach, Ni-based insertion serves as a diffusion barrier, because the Ni-Sn reaction is two orders slower than the $\mathrm{Cu}-$ Sn reaction [3]. Electroless nickel/ electroless palladium/ immersion gold (ENEPIG) is the most cost effective candidate due to the thickness of the immersion gold layer among the commercial surface finish is the thinnest. The thickness of this layer, which is projected to be about $0.1 \mu \mathrm{m}$, can prevent Ni oxidation [4]. In addition, the RoHS (Restriction of Hazardous Substances) Pb-free requirements have made it necessary once again to revisit all available surface finishes, and ENEPIG has again come under close scrutiny as the industry evaluated its capabilities using Pb-free assembly conditions [5].

Therefore, this study is performed to examine the interfacial reaction between $\mathrm{Sn}-4.0 \mathrm{Ag}-0.5 \mathrm{Cu}$ lead-free solders and EN(P)EPIG and EN(B)EPIG surface finishes on intermetallic growth and thickness. Besides that, the effect of isothermal aging duration also has been investigated.

\section{Experimental Procedure}

The soldering reaction between $\mathrm{Sn}-4.0 \mathrm{Ag}-0.5 \mathrm{Cu}$ (SAC405) and EN(P)EPIG and EN(B)EPIG surface finishes were examined in this study. The copper polymer sandwich substrate (FR-4) with dimensions $45 \times 50 \times 1 \mathrm{~mm}$ was prepared and then was subjected to a pretreatment process in order 
to remove oxides and activate the copper substrate surface before both of EN(P)EPIG and EN(B)EPIG plating process is started. The Ni-P and Ni-P solution was conducted at $85^{\circ} \mathrm{C}$ and after that, electroless palladium were applied on Ni layer and followed by deposited with gold layer through immersion plating without any pretreatment except rinsing in running tap water with temperature was set up at $45^{\circ} \mathrm{C}$ and $93^{\circ} \mathrm{C}$ respectively. Then, all samples were laminated with a layer of solder mask to restrict the molten solder from flat spreading during reflow. Next step is the solder mask together with the patterned film was cured by ultraviolet (UV) light in order to produce small openings. After curing samples, a thin layer of no-clean flux is applied onto the substrate to remove the oxide layer and also to improve the wetting of molten solder during reflow. Then, the substrates were manually populated with solder balls with a diameter of $500 \mu \mathrm{m}$ arranged in several rows. Bonding to form the solder joints was made by reflow soldering in a furnace at temperature $\sim 230^{\circ} \mathrm{C}$. Then, each sample was subjected to aging treatment at $150^{\circ} \mathrm{C}$ for 250 hours, 1000 hours and 2000 hours. Characterisation of samples involved both at top surface and cross section of solder joints. Several techniques including optical microscopy, NIKON optical microscope, scanning electron microscopy (SEM) and energy dispersive $\mathrm{x}$-ray analysis (EDX), image analyzer and field emission scanning electron microscope (FESEM) were used for the intermetallics characterization.

\section{Results and discussion}

During reflow soldering process, the interfacial reaction between the SAC405 on the EN(P)EPIG and EN(B)EPIG surface finishes was shown that a presence of a ring shape of the intermetallics layer varying sizes. Fig.1 shows a schematic diagram of morphology of the intermetallic layer formed between SAC405 solders investigated on both finishes. It shows different regions of IMCs varying from centre to the edge of the solder ball. This so called beach mark has been reported previous researcher [6,7]. The IMCs commonly formed in lead-free solders are $(\mathrm{Cu}, \mathrm{Ni})_{6} \mathrm{Sn}_{5}$, $(\mathrm{Ni}, \mathrm{Cu})_{3} \mathrm{Sn}_{4}$, and $\mathrm{Ni}_{3} \mathrm{Sn}_{4}$. The solder composition may not be homogeneous throughout the solder volume and thus the availability of $\mathrm{Cu}$ in the solder may vary between the centre and edge of solder joint. This gives a different type of IMCs formation at the center and at the edge.

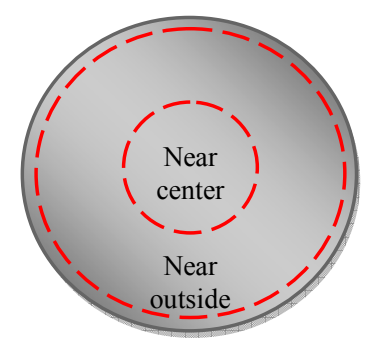

Fig. 1: (a) Schematic diagram of different area of solder ball

The intermetallic formation at the interface during soldering was represented in Fig, 2. It was clearly seen that $(\mathrm{Cu}, \mathrm{Ni})_{6} \mathrm{Sn}_{5}$ intermetallic compound (IMC) was dominates at a near centre of Ni-P as well as Ni-B. These IMC's exhibited rod-like and/or needle-shape morphology. The composition of intermetallics was confirmed by energy dispersive X-ray analysis (EDX). Similar results were obtained by others researcher [8,9,10]. Besides that, a needle-like of $(\mathrm{Ni}, \mathrm{Cu})_{3} \mathrm{Sn}_{4}$ was observed near outside area/Ni-B. It is because of the cooling rate at the near outside region at which the IMC solidifies faster than at near center region. Another reason is that $\mathrm{Cu}$ concentration at the outside region may be not high enough to form $(\mathrm{Cu}, \mathrm{Ni})_{6} \mathrm{Sn}_{5}$ compared to near center region. Although the $\mathrm{Ni}$ layer may still remain on the $\mathrm{Cu}$ surface at the outside region, the $\mathrm{Ni}$ atoms from the substrate continuously dissolve into the molten solder. This would dilute the $\mathrm{Cu}$ concentration in the molten solder. The present results are also consistent with those of Yen et al. [11]. Furthermore, V shapeplate-like $\mathrm{Ni}_{2} \mathrm{Sn}$ IMC was observed at near outside region while flower-like $(\mathrm{Ni}, \mathrm{Cu})_{3} \mathrm{Sn}_{4} \mathrm{IMC}$ as can 
be seen in Fig. 2(e). However, the formation of these flower-like IMC is still not fully understood at the moment.

Besides that, small amount of $\mathrm{Pd}$ was also found in the $(\mathrm{Cu}, \mathrm{Ni}, \mathrm{Pd})_{6} \mathrm{Sn}_{5}$ as shown in Fig. 2(a), implying that Pd was likely to dissolve in the IMC layer. This phenomenon occurred because Pd dissolves in molten solder but does not move very far away from the interface between solder and substrate during reflow soldering. However, during solidification Pd will combine with the available Sn to form $\mathrm{PdSn}_{4}$ IMC. Since PdSn $\mathrm{IMC}_{4}$ is not as stable IMC as $\mathrm{Ag}_{3} \mathrm{Sn}$ IMC, Pd will combine with $\mathrm{Ni}$ and $\mathrm{Cu}$ elements where $\mathrm{Ni}$ is also dissolved from Ni-P layer and $\mathrm{Cu}$ from solder alloy in the same time to form $(\mathrm{Cu}, \mathrm{Pd}, \mathrm{Ni})_{6} \mathrm{Sn}_{5}$ or $(\mathrm{Ni}, \mathrm{Pd}, \mathrm{Cu})_{3} \mathrm{Sn}_{4}$ depending on the availability of $\mathrm{Ni}$ or $\mathrm{Cu}$ atom during interfacial reaction. This is in good agreement with Tseng et al. [12] and Azmah [6]. Moreover, the presence of the thin Pd layer in the ENEPIG finish may have suppressed the growth of the interfacial IMC layer and the consumption of the $\mathrm{Ni}(\mathrm{P})$ layer, resulting in the superior interfacial stability of the solder joint during prolonged reflowing at $260^{\circ} \mathrm{C}$ [8]. The results seem to reconcile well with the above statement as the intermetallics formed on ENEPIG finish are more refined than those observed on ENIG finishes.
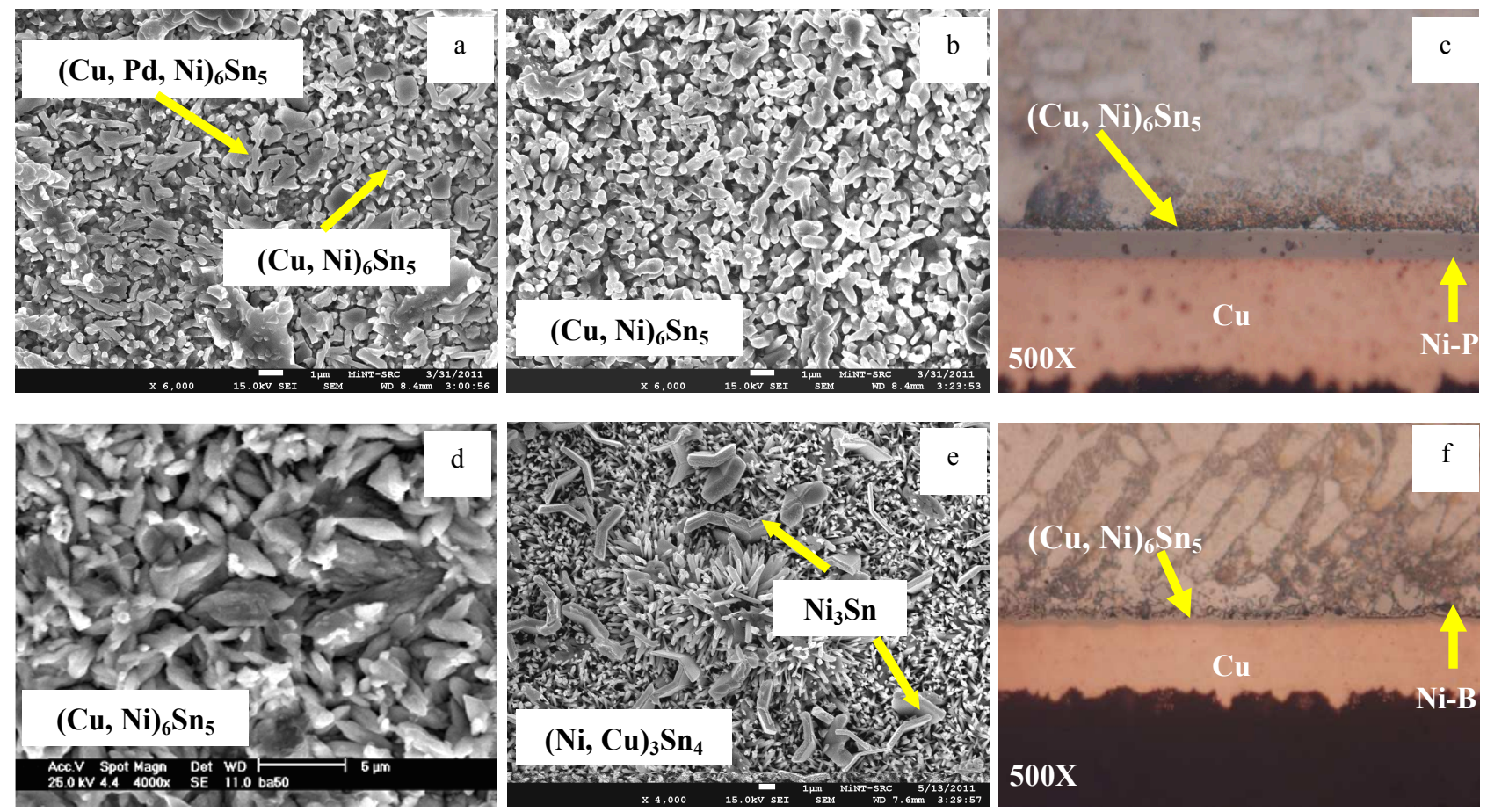

Fig. 2 SEM top surface and cross-sectional view of Sn-4Ag-0.5Cu solder with $\varnothing 500 \mu \mathrm{m}$ after reflow soldering (a) near centre area/Ni-P (b) near outside area/Ni-P (c) intermetallics on Ni-P (d) near centre area/Ni-B (e) near outside area/Ni-B (f) intermetallics on Ni-B

When the substrate is exposed to isothermal aging, the intermetallic formation (IMC) formed during reflow soldering will grew continually but at a much slower rate as can be seen in fig. 2(c) and fig. 2(f) for as reflowed condition compared to fig. 3(e) and fig. 3(f) for aged condition. According to Fig. 3, only $(\mathrm{Cu}, \mathrm{Ni})_{6} \mathrm{Sn}_{5} \mathrm{IMC}$ was observed at near centre for both finishes. Based on ternary diagram, both IMCs, $(\mathrm{Cu}, \mathrm{Ni})_{6} \mathrm{Sn}_{5}$ and $(\mathrm{Ni}, \mathrm{Cu})_{3} \mathrm{Sn}_{4}$ are based on the $\mathrm{Cu}_{6} \mathrm{Sn}_{5}$ and $\mathrm{Ni}_{3} \mathrm{Sn}_{4}$ crystal structures, respectively where $(\mathrm{Cu}, \mathrm{Ni})_{6} \mathrm{Sn}_{5}$ and $(\mathrm{Ni}, \mathrm{Cu})_{3} \mathrm{Sn}_{4}$ are stable ternary formed at the interface. It is evident from the top view of IMC layers that aging treatment induced changes in the morphology of intermetallics. In terms of IMC composition, the intermetallics are predominantly of $\mathrm{rod} /$ needle-like or platelet-like of $(\mathrm{Cu}, \mathrm{Ni})_{6} \mathrm{Sn}_{5}$ was observed at near center region and was found to be stable IMC even exposed at higher aging duration. This is because $\mathrm{Cu}$ has high enough atoms to diffuse during interfacial reaction between $\mathrm{Ni}$ and $\mathrm{Sn}-\mathrm{Ag}-\mathrm{Cu}$ solder. However, overall aging treatment renders the IMC grains rounder, bigger and more compact. Huang et al. [13] reported that 
with increasing aging time, the $\left(\mathrm{Cu}, \mathrm{Ni}_{6} \mathrm{Sn}_{5}\right.$ IMC grains gradually coarsened into stout rods in morphology.

Besides that, the formation of $\mathrm{Ag}_{3} \mathrm{Sn}$ also was observed at the interface as represents in Fig. 3(a) and 3(b). During solid-state reaction, there is another intermetallic will form in the bulk solder known as $\mathrm{Ag}_{3} \mathrm{Sn}$. This $\mathrm{Ag}_{3} \mathrm{Sn}$ IMC mostly is formed in block-type and/or granular type morphology just ahead of the interface.
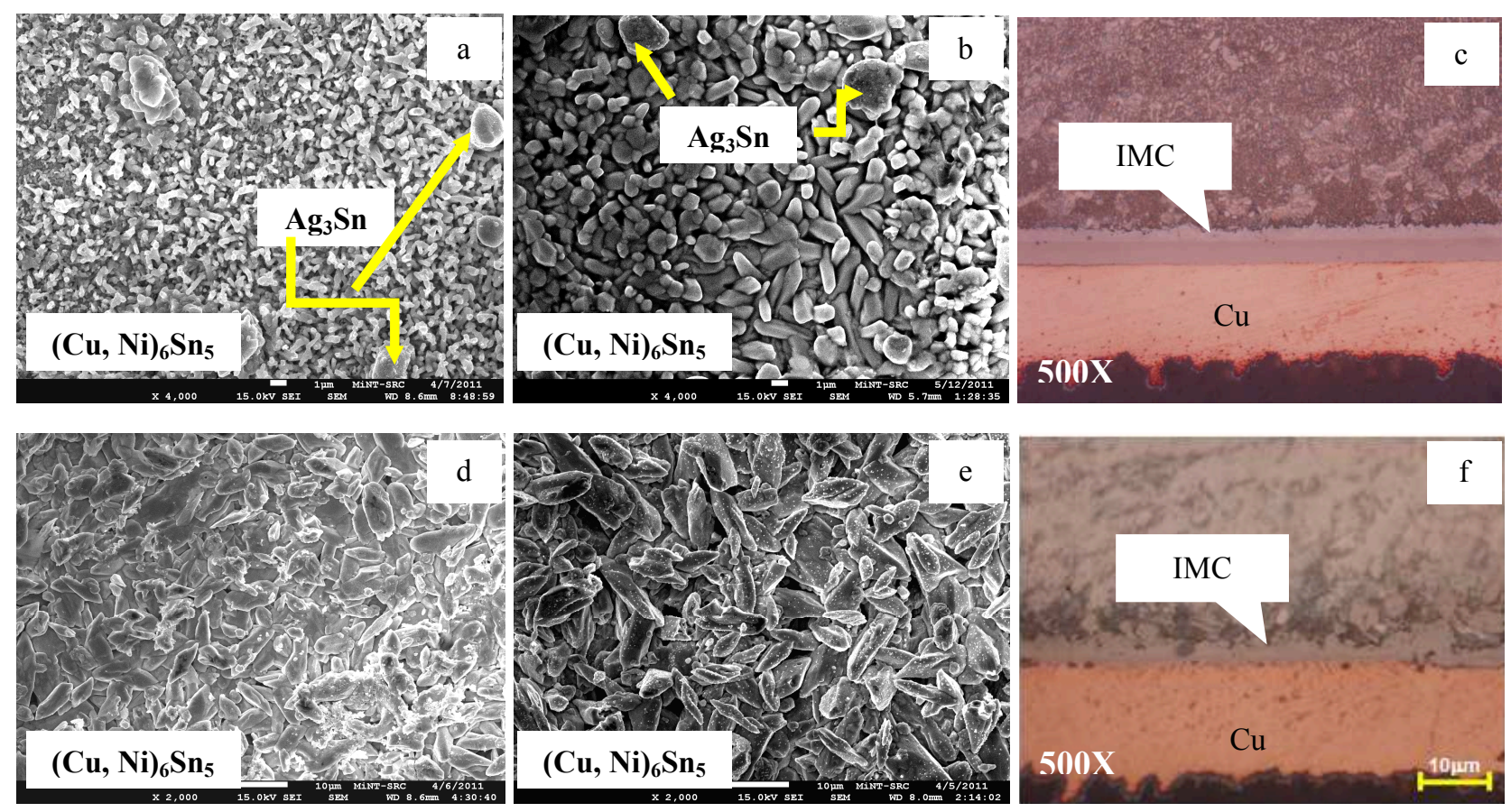

Fig. $3 \mathrm{SEM}$ top surface of Sn-4Ag-0.5Cu solder with solder size $\varnothing 500$ aged at $150^{\circ} \mathrm{C}$ (a) aging 250 hours on Ni-P (b) aging 2000 hours on Ni-P (c) cross-sectional SAC/Ni-P of 2000 hours (d) aging 250 hours on Ni-B (e) aging 2000 hours on Ni-B (f) cross-sectional SAC/Ni-B of 2000 hours

Furthermore, when comparing interfacial reactions of both surface finishes with SAC405 solder alloy, the IMC's formed on EN(P)EPIG exhibited much slower growth rates compared to IMC's formed on electroless EN(B)EPIG during aging at $150^{\circ} \mathrm{C}$. This can be attributed to the presence of $\mathrm{Pd}$ layer between Ni-P and Au layers, which forms Pd-Sn IMC and resulting in slower IMC formation. This was clearly confirmed by IMC thickness and growth kinetics results as illustrated in Fig. 4.
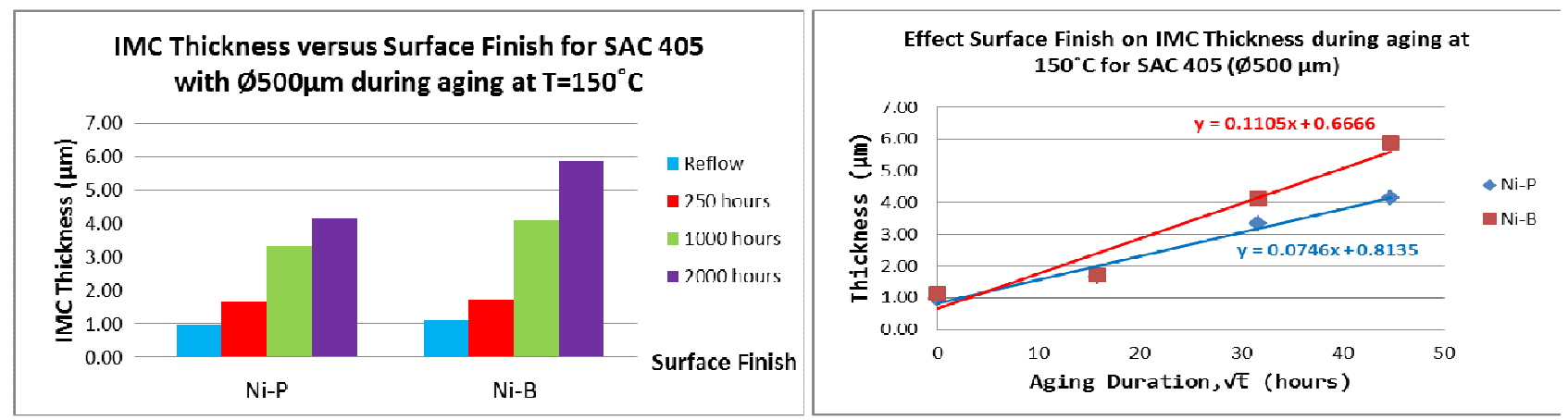

Fig. 4 (a) IMC thickness versus surface finish with $\varnothing 500 \mu \mathrm{m}$ during aging at $150^{\circ} \mathrm{C}$ for SAC 405 solder (b) IMC growth kinetics on EN(P)EPIG and EN(B)EPIG finishes 


\section{Summary}

From the research, the $(\mathrm{Cu}, \mathrm{Ni})_{6} \mathrm{Sn}_{5}$ intermetallic compound (IMC) is dominated at near centre of solder meanwhile $(\mathrm{Ni}, \mathrm{Cu})_{3} \mathrm{Sn}_{4} \mathrm{IMC}$ is dominated at near outside of solder ball after reflow soldering and isothermal aging process. Moreover, aging time resulted in an increase in thickness and changed the morphology into more spherical, dense and large grain size. Analysis by optical microscope revealed that the IMC thickness of EN(B)EPIG produced thicker IMC compared to EN(P)EPIG surface finish during reflow as well as isothermal aging.

\section{Acknowledgments}

This work was financially supported by Universiti Tun Hussein Onn Malaysia (UTHM)(R030), Universiti Teknologi Malaysia, Microelectronics and Nanotechnology-Shamsuddin Research Centre (Mint-SRC, UTHM) and Faculty of Mechanical and Manufacturing Engineering (FKMP, UTHM) for providing the research facilities.

\section{References}

[1] Xia, Y. \& Xie, X., Reliability of lead-free solder joints with different PCB surface finishes under thermal cycling. Journal of Alloys and Compounds, 454(2008), Issues 1-2, 174-179

[2] Tsao LC, An investigation of microstructure and mechanical properties of novel $\mathrm{Sn}-3.5 \mathrm{Ag}-$ $0.5 \mathrm{Cu}-\mathrm{xTiO} 2$ composite solders as functions of alloy composition and cooling rate. Mater Sci Eng A (2011) 41-8.

[3] K.N. Tu, K. Zheng, Tin-lead ( $\mathrm{SnPb})$ solder reaction in flip chip technology Mater. Sci. Eng. R34 (2001)1-58

[4] C.-H. Fu, L.-Y. Hung, D.-S. Jiang, C.-C. Chang, Y.-P. Wang, C.-S. Hsiao, Evaluation of new substrate finish: electroless nickel/electroless palladium/immersion gold (ENEPIG), in: Electronic Components and Technology Conference (2008) 1931-1935.

[5] G. Milad \& M. Orduz. Surface finishes in a lead-free world: RoHS regulations force alternative formulations, processes. Metal Finishing, 105 (2007) 25-28

[6] Azmah Hanim, M.A.. Interfacial Reaction Between Sn-37Pb and Sn-4Ag-0.5Cu Solder On Different Surface Finish. Doctor Philosophy, Universiti Teknologi Malaysia, Skudai, (2007)

[7] Ourdjini, A., Azmah Hanim, M.A. Siti Aisha, I. and Chin, Y.T. Effect of Surface Finish Metallurgy on Intermetallic Compounds during Soldering with Sn-Ag-Cu Solders. $33^{\text {rd }}$ International Conference on electronics Manufacturing and Technology (IEMT-IEEE), 4-6 November 2008, Penang, Malaysia

[8] Yoon, J.W., Noh, B.I and Jung, S.B. Comparative Study of ENIG and ENEPIG as Surface Finishes for a Sn-Ag-Cu Solder Joint. Journal of Electronic Materials (2011).

[9] Yen, Y.W, Tsai, P.H, Fang, Y.K, Lo, S.C., Hsieh, Y.P. and Lee, C. Interfacial reactions on Pbfree solders with $\mathrm{Au} / \mathrm{Pd} / \mathrm{Ni} / \mathrm{Cu}$ multilayer substrates. Journal Of Alloys And Compounds. 503(2010) 25-30

[10] Ho, C. E., Lin Y.W., Yang, S.C., Kao, C.R. and Jiang, D.S.. Effects of Limited Cu Supply on Soldering Reactions between $\mathrm{SnAgCu}$ and Ni. Journal of Electronic Materials. ProQuest Science Journals, 35 (2006) 1017.

[11] Yen, Y.W., Chiang, Y.C, Jao, C.C., Liaw, D.W., Lo, S.C. and Lee, C. Interfacial reactions and mechanical properties between SAC405 and SAC405-0.05Ni-0.01Ge lead free solders with $\mathrm{Au} / \mathrm{Ni} / \mathrm{Cu}$ substrate. Journal of Alloys and Compounds. 506 (2011) 4595-4602.

[12] Tseng, C-F., Lee, T.K., Ramakrishna, G., Liu, K.C. and Duh, J.G.. Materials Letters. 65(2011) 3216-3218

[13] Huang, Z.F., Conway, P.P, Jung, E., Thomson, R.C, Liu, C.Q, and Loeher T.. Reliability Issues in Pb-Free Solder Joint Miniaturization. Journal of Electronic Materials. 35(2006)1761-1772. 